\title{
FUNCTIONAL RESPONSES OF Encarsia perniciosi (TOWER) AND Encarsia citrina (CRAW.) TO Quadraspidiotus perniciosus (COMSTOCK) IN RESPONSE TO TEMPERATURE \\ Bayoumy, M. H. ${ }^{1,2}$; A. I. Abd El-Kareim ${ }^{2 ;}$; A. H. Abdel-Salam²; N. F. Abdel-Baky ${ }^{2}$ and A. Schopf ${ }^{1}$ \\ 1- Forest Pathology and Forest Protection (IFFF), Institute of Forest Entomology, Univ. of Natural Resources and Applied Life Sciences (BOKU), Vienna 1190, Austria. \\ 2- Economic Entomology Dept., Fac. of Agric., Mansoura Univ., B. O. Box 35516, Mansoura, Egypt. \\ Corresponding author: marsamarium@yahoo.com
}

\begin{abstract}
Prior to the field release of natural enemies in bio-control programs, it is essential to evaluate their efficiency under laboratory conditions. One informative method is the functional response of natural enemy to host density. Moreover, temperature is an important factor that affects the efficiency of bio-control agent. First, the effect of densities of the diaspidid host, Quadraspidiotus perniciosus (Comstock) on functional response types of the aphelinid parasitoids, Encarsia perniciosi (Tower) and Encarsia citrina (Craw.) was examined. Secondly, we examined the temperaturedependent functional response for the $E$. perniciosi. Three temperatures $(15,20$, and $25^{\circ} \mathrm{C}$ ) and five host densities $(10,15,20,25$ and 30 scales) were used. At each temperature, 10 to $301^{\text {st }}$ instars were exposed to a female E. perniciosi for a $24 \mathrm{~h}$. In the first experiment, the decelerating rate of decrease in the parasitism rate of $E$. perniciosi indicated a type II response, whereas the absence of significant dependence on host density by $E$. citrina indicated a type I response. In the second experiment, E. perniciosi exhibited a type II response (inverse-density dependent parasitism rate) at all temperatures. Therefore, releasing the E. perniciosi in the beginning of growing season on low host populations can provide more control. The attack rate of $E$. perniciosi increased with increasing temperatures from 15 to $25^{\circ} \mathrm{C}$, whereas the handling time decreased. $25^{\circ} \mathrm{C}$ seems to be the most suitable condition for Encarsia activity and reproduction. This implies that E. perniciosi is well adapted to relatively moderate temperature, which allows its implementation as a bio-control agent of $Q$. perniciosus during the growing season even in countries of higher latitudes.
\end{abstract}

Keywords: Encarsia, Functional response, Handling time, Instantaneous attack rate.

\section{INTRODUCTION}

The San Jose scale, Quadraspidiotus peniciosus (Comstock), is an important pest in several countries of the world (e.g., Kozàr et al. 1982; Jahn and Polesny 1999; Abdel-Kareim et al. 2005). Since 2000, it has been recorded for the first time in Egypt infesting apricot trees (Abdel-Kareim et al. 2005), while the first record in Austria orchards goes back to 1931 (Jahn and Polesny 1999). It attacks at least 34 families of hosts (over 700 species) and can be particularly problematic in stone fruits, apple, pear, apricot, and cherry 
trees (Kaiser and Sheard 2006). The cosmopolitan polyphagous aphelinid wasp, Encarsia citrina Craw. has a worldwide distribution (Malipatil et al. 2000). It is a primary, solitary, proovigenic, and thelytokous endoparasitoid (Malipatil et al. 2000). It is capable of parasitizing both male and female $Q$. perniciosus (Matadha et al. 2005). Baroffio (1997) describes the biology of Encarsia perniciosi (Tower), which was introduced for biological control of $Q$. perniciosus in 1949. Encarsia perniciosi can attack multiple scale species, but $Q$. perniciosus is the only common host available in our study area. Although successes and failures of $E$. perniciosi in classical biological control for $Q$. perniciosus have been mentioned in different studies (e.g., Jolly 1962; Sahai and Joshi 1965; Neuffer 1990), this study is a first report that concentrates on the suitability of E. perniciosi for using it in management for Q. perniciosus.

Prior to the release of natural enemies in a biological control program, it is essential to evaluate their efficiency under laboratory conditions. One informative method for assessing the efficacy of natural enemies is the study of their foraging behavior including functional response (Fathipour et al. 2006; Bayoumy 2009). Functional response is the number of hosts successfully attacked per parasitoid as a function of host density (Solomon 1949). It is a commonly measured attribute of natural enemies. Practitioners of inundative biological control may use functional response to estimate the appropriate numbers of biological control agents to be released in order to bring about an immediate reduction in pest numbers (Mills and Lacan 2004). Holling (1965) proposed three types of functional responses: type I, a linear rise to a plateau; type II, a curvilinear rise to a plateau; and type III, a sigmoid curve rising to a plateau which then levels off under the influence of handling time or satiation (Hassell 2000). Among the types of functional responses, type II and III have received the most attention (Allahyari 2004). Holling (1961) divided the functional response into several basic and subsidiary components. The attack rate (a) can be considered to be a function of: (1) the reaction distance of the parasitoid, i.e., the maximum distance at which the parasitoid will react by attacking host; (2) the speed of movement of parasitoid and host; and (3) the proportion of attacks that are successful. The handling time $\left(T_{h}\right)$ can be considered to be a function of: (1) the time spent pursuing an individual host; (2) the time spent investigating and probing each host; and (3) the time spent drilling each host. The time as host and parasitoid exposure (T) can be considered to be a function of: (1) time in nonovipositing activities; and (2) time in ovipositing-related activities (i.e., $\mathrm{T}_{\mathrm{h}}$ ).

Climatic adaptation is an important criterion for selecting potential biological control agents (van Lenteren 1986). Although field-testing of natural enemies for the selection for climatic adaptation can be very time consuming, especially if several candidates are involved, laboratory and greenhouse studies are useful for choosing a suitable candidate (Pak and van Lenteren 1988). Ambient temperature is an important factor influenced the functional response of a natural enemy (Pakyari et al. 2009). Lack of success in biological control programs has often been caused by high mortality of natural enemies due to climatic extremes (van Driesche and Bellows 1996). Bayoumy et al. (2009) studied the influence of temperature on the searching rate of $E$. citrina, while no detailed information has been reported on $E$. 
perniciosi. Up to now, the role of natural enemies in the management of $Q$. perniciosus in Egypt is low due to the influence of temperature on the synchronization between developmental cycles of $Q$. perniciosus and its parasitoids (Abdel-Kareim et al. 2005), resulting in high dispersal of the insect to other hosts and regions (Moursi et al. 2008). The best way to judge the quality of a natural enemy for the future biocontrol programs is evaluating its efficiency against the pest in one of the native homelands prior to its introduction in a new area (like Egypt). Through the comprehensive evaluation for parasitoids of Q. perniciosus in Egypt and followed in Austria for selecting the parasitoid which could be provide more control, functional response in response to temperature was used to determine the most suitable temperature for the efficient parasitoid, E. perniciosi. First, an experiment was conducted to determine the functional response type of $E$. perniciosi and E. citrina. Next, based on the data of the first study, the temperature-dependent functional response of E. perniciosi to $Q$. perniciosus was evaluated. The results from this study might be contribute in the understanding of the response of $E$. perniciosi to $Q$. perniciosus under different environmental conditions, and thus this will useful be in development of future mass rearing and bio-control programs.

\section{MATERIALS AND METHODS}

\section{Source of parasitoids and colony maintenance}

Laboratory colonies of $E$. perniciosi and E. citrina were started by obtaining individuals from $Q$. perniciosus infested apple trees, located in the university farm and from euonymus scale, Unaspis euonymi (Comstock)infested Japanese euonymus, Euonymus japonicus (L.), located in the home gardens of Vienna, respectively. Small colonies of the parasitoid species were reared on infested green apple fruits with $Q$. perniciosus in plastic boxes $(10 \times 5 \times 10 \mathrm{~cm})$ in temperature controlled cabinets at $20 \pm 1^{\circ} \mathrm{C}$ and 16:8 (L:D photoperiod). Each box contained one apple fruit. To rear each parasitoid species, 10 apple fruits harbored 5-10-day-old scales were exposed to wasp oviposition by 20 females ( 2 female/fruit) of E. perniciosi and 100 females (10 female/fruit) of $E$. citrina every three days to maintain a constant colony source. Water was provided in 5-ml plastic cups with cotton wicks and honey streaked on small self-adhesive paper strips to serve as a food source for the parasitoids. Parasitoids were obtained by isolating them in the pupal stage within the host body from apple fruits bearing parasitized scales using a pin and a small camel's- hair brush. Because Encarsia is an endoparasitoid, pupae within host body could be isolated from host plant material without disrupting their development. Scale covers were lifted with an insect hand pin, and when a parasitoid pupa was found, it was picked up with a small camel's hair brush and placed in small plastic tubes $(3 \mathrm{~cm}$ in height and 0.5 $\mathrm{cm}$ in diameter) provided with honey on its cover. The tubes were marked and kept in the laboratory until adult emergence.

\section{Functional response type of $E$. perniciosi and $E$. citrina}

Through the peak of crawler (i.e., $1^{\text {st }}$ instar) emergence, unknown numbers of $Q$. perniciosus crawlers were transferred to non-infested green 
apple fruits using a small hand pin in the same day of their emergence. Two days later, the fruits were investigated to determine the numbers of settled $1^{\text {st }}$ instar. Scales in excess of the specified densities $(5,10,15,20$ and 25 scales/fruit) were removed.

The female wasps ( $48 \mathrm{~h}$ old) were released on fruits infested with $Q$. perniciosus. E. perniciosi was released when the host was 3-8 days- old (Sahai and Joshi 1965) and E. citrina was released when the host was 10 days old (Matadha et al. 2005; Bayoumy et al. 2009). Five densities of scale insect $(5,10,15,20$, and 25) were chosen for determining the functional response of the two parasitoid species. Each parasitoid female was released on each host density in plastic boxes $(10 \times 10 \times 20 \mathrm{~cm})$ for $24 \mathrm{~h}$ at room temperature (23/14 ${ }^{\circ} \mathrm{C}$ Max.:Man.). Each box contained one fruit infested with the required numbers of host. Each treatment was replicated ten times. To measure the parasitism, following the removal of the female parasitoids, the exposed scales were incubated at $25 \pm 1^{\circ} \mathrm{C}$ and $16 \mathrm{~L}$ : 8D photoperiod until the pupal stage $(\approx 17 \mathrm{~d})$ of the parasitoid. Each parasitoid selected for the experiment was used only once. Only replicates with the parasitoid surviving within $24 \mathrm{hr}$. were used to determine the functional response. In this experiment, we sought to select the wasp has an effective type of response to study its temperature-dependent functional response in the next step.

\section{Temperature-dependent functional response of $E$. perniciosi}

Influence of three temperatures $\left(15,20\right.$, and $\left.25^{\circ} \mathrm{C}\right)$ and host densities $(10,15,20,25$, and 30 individuals) on progeny distributions for females of $E$. perniciosi was evaluated. One active female ( $48 \mathrm{~h}$ old) was transferred to each density of $Q$. perniciosus at each temperature in the above mentioned boxes for $24 \mathrm{hr}$ ovipositing period. Each box contained one apple fruit and each treatment was replicated five times. Following the removal of the female parasitoids, the exposed scales were incubated at $25 \pm 1^{\circ} \mathrm{C}$ and 18:6 $\mathrm{h}(\mathrm{L}: \mathrm{D}$ photoperiod) until the parasitoid's egg developed to the pupal stage.

\section{Data processing and analysis}

To determine the type of functional response, the data were fitted to a linear model In $[p /(1-p)] \alpha+\beta$ No/P (i) using SPSS 15.0 for windows (SPSS 2006) to establish the relationship between the proportion of host scales attacked $\left(p=N_{a} / P\right)$ to scale density per parasitoid $\left(N_{0} / P\right)$ (Trexler et al. 1988; Mills and Lacan 2004). The absence of a significant dependence of $p$ on $N_{0} / P$ is attributed to a type I response, a significant negative dependence to a type II, and a positive dependence to a type III response (Mills and Lacan 2004).

Type I (Nicholson and Bailey 1935): $\mathrm{N}_{\mathrm{a}} / \mathrm{P}=\mathrm{N}_{0} / \mathrm{P}\{1-\exp (-\mathrm{aP})\}$ (ii) for $N_{0} \leq b P / a$ and $N_{a} / P=b$ for $N_{0}>b P / a$ and type II (Holling 1959): $\mathrm{N}_{\mathrm{a}}=\mathrm{aTN} \mathrm{N}_{0} / 1+\mathrm{aTh} \mathrm{N}_{0}$ (iii), where $\mathrm{N}_{\mathrm{a}}$ is the number of scale insects attacked, $\mathrm{N}_{0}$ is host scale density available, $\mathrm{P}$ is parasitoid density, $\mathrm{a}$ is instantaneous attack rate or area covered by a parasitoid in a given amount of time (1day), and $b$ is the maximum number of scales that can be attacked in the given time. For type I functional response (for $\mathrm{N} \leq \mathrm{bP} / \mathrm{a}$ ), the parameter a was estimated by nonlinear least square regression by fitting the type I model to data between 5 and 20 hosts and the parameter $b$ (for $\mathrm{N}>b P / a$ ) was estimated from the mean numbers of scale insects attacked $\left(\mathrm{Na}_{\mathrm{a}}\right)$ at host 
density of 30 (Mills and Lacan 2004). The handling time of E. citrina could be estimated using the relationship $b=T / T_{h}$ (Getz and Mills 1996).

Data analysis for studying the influence of temperature on functional response of E. perniciosi includes two steps (Juliano 2001; Mohaghegh et al. 2001): (1) the shape (i.e., the type) of functional response must be determined. Usually, it is difficult to discriminate between type II and III functional responses (Trexler et al. 1988). Trexler et al. (1988) showed that logistic regressions of proportion of hosts parasitized $\left(\mathrm{N}_{\mathrm{a}}\right)$ against the number of hosts offered $\left(\mathrm{N}_{0}\right)$ provided a more powerful and accurate means of distinguishing between type II or III functional responses compared to analysis of the typical functional response curve (i.e., $\mathrm{N}_{\mathrm{a}}$ against $\mathrm{N}_{0}$ ). Briefly, to determine the shape of functional response, a polynomial regression (Juliano 2001) is fitted to observed proportions of scales parasitized $\mathrm{N}_{\mathrm{a}}$ against $N_{0}$ at each temperature, and the shape of this polynomial fit is determined. If the proportion parasitized initially increases with the number of hosts, this is sufficient to identify a type III functional response. If, on the other hand, the proportion parasitized declines monotonically with the number of hosts, this is sufficient to identify a type II response. The polynomial function was fitted to the data on the proportion of scale attacked as.

$$
\overline{\mathrm{N}_{a}}=\frac{\exp \left(\mathrm{P}_{0}+\mathrm{P}_{1} \mathrm{~N}_{0}+\mathrm{P}_{2} \mathrm{~N}_{0}^{2}+\mathrm{P}_{3} \mathrm{~N}_{0}^{3}\right)}{1+\exp \left(\mathrm{P}_{0}+\mathrm{P}_{1} \mathrm{~N}_{0}+\mathrm{P}_{2} \mathrm{~N}_{0}{ }^{2}+\mathrm{P}_{3} \mathrm{~N}_{0}{ }^{3}\right)}
$$

Where the parameters $P_{0}, P_{1}, P_{2}$, and $P_{3}$ are the constant, linear, quadratic, and cubic parameters, respectively, related to the slope of the curve. The sign of $P_{1}$ and $P_{2}$ can used to distinguish the shape of the curves (Juliano 2001). The slope of $P_{1}$ for type III is accelerating [i.e., a significant positive linear parameter $\left(\mathrm{P}_{1}\right)$ and a negative quadratic parameter $\left.\left(\mathrm{P}_{2}\right)\right]$ and the type II is declining [i.e., a significant negative linear parameter $\left.\left(\mathrm{P}_{1}\right)\right]$. (2) after the determination of the shape of the curve (i.e., type), the parameters a (the coefficient of attack rate), Th (handling time), and b (the asymptote of functional response curve or the maximum number of hosts parasitized) of type II response were estimated using the disc equation (the most widely used model for describing the functional response of parasitoid / predator) given by Holling (1959) as mentioned above and using SPSS procedure.

To study the effect of temperature and host densities (i.e., second experiment) and their interaction on proportion of scale parasitized per female and day by E. perniciosi, two-way followed by one-way ANOVA was performed. Both ANOVA were followed by least significant difference at $\alpha=0.05$ comparisons using Duncan's Multiple Range test. Statistics were conducted using CoStat 6.3 software for windows (CoStat 2005).

\section{RESULTS}

\section{Functional response type of E. perniciosi and E. citrina}

The analysis of the proportion of San Jose scales attacked (p) by $E$. citrina at different scale density $\left(\mathrm{N}_{0} / \mathrm{P}\right)$ showed no significant dependence $\left(F_{1,4}=7.84 ; P>0.05\right)$ (Fig. 1a) indicating a type I functional response by the parasitoid (Fig. 1b). On the other hand, E. perniciosi showed a significant negative dependence $\left(F_{1,4}=81.4 ; \quad P<0.001\right)$ of the proportion of scales 
attacked on scale density (Fig. 1a) indicating a type II response (Fig 1b). With increasing host density, $E$. perniciosi significantly parasitized higher proportions of $Q$. perniciosus than $E$. citrina (Fig. $1 ; P<0.001$ ). On average, $E$. perniciosi parasitized $43 \%$ of $Q$. perniciosus compared to $18 \%$ by $E$. citrina.

The estimated values of instantaneous attack rate (a) and handling time $\left(T_{h}\right)$, and maximum number of parasitized scales using Nicholson and Bailey (i.e, type I) and Holling (i.e., type II) equations were $0.19 \pm 0.01$, $6.08 \pm 0.51 \mathrm{hr}$., and $3.95 \pm 0.51$ scales $\left(r^{2}=0.93\right)$ for $E$. citrina and $1.56 \pm 0.41$, $3.81 \pm 0.39 \mathrm{hr}$, and $6.31 \pm 0.64$ scales $\left(F_{1,24}=15.86 ; P=0.03 ; r^{2}=0.84\right)$ for $E$. perniciosi, respectively.
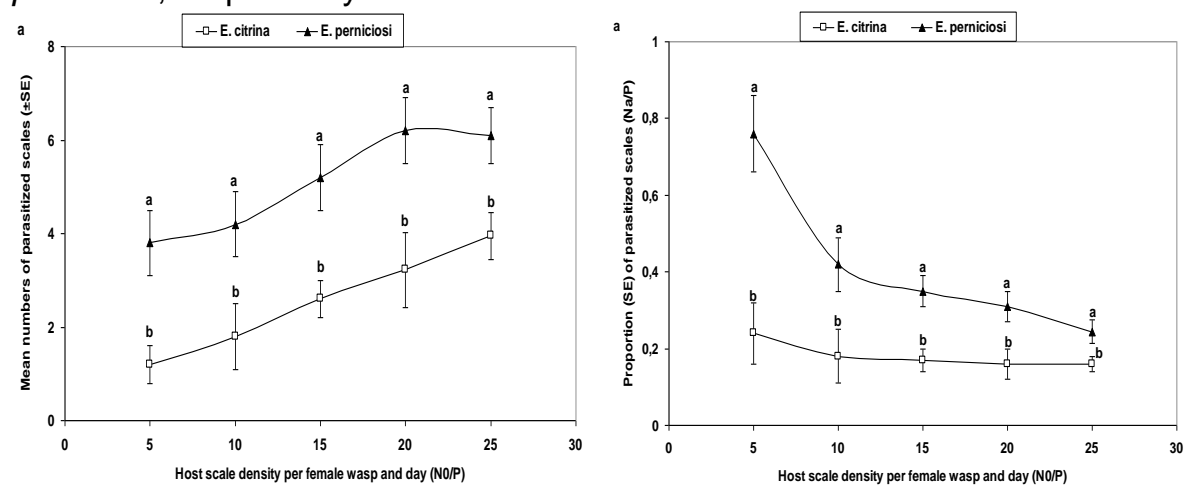

Fig. 1. Functional response curves (a) and proportion of parasitized scales (b) by $E$. citrina (type I) and E. perniciosi (type II) at various host density of $Q$. perniciosus. Comparisons labeled with the diverse letters are significantly different $(P<0.001)$.

\section{Temperature-dependent functional response of $E$. perniciosi}

By increasing temperature and host density, the number of scales parasitized by $E$. perniciosi increased (Fig. 2a-C). Correspondingly, the proportion of scales parasitized decreased as the number of available scales increased (Fig. 2d-f). The accelerated decrease in the proportion of $Q$. perniciosus scales parasitized in relation to the host density and temperature best-fitted the description of a type II functional response. At the three tested temperatures, the significant negative parameter of $\mathrm{P}_{1}$ suggested that the slopes of the functional response curves were declining, which is characteristics of a type II functional response (Table 1). By plotting a type II functional response model to the number and proportion of scales parasitized at each tested temperature, the lines fitted well the data (Fig. 2). Therefore, the Holling's model was fitted separately for each experimental temperature in order to measure the attack rate and handling time.

The daily rate of oviposition per female of $E$. perniciosi was significantly increased when temperature and host density increased $(P<0.001)$. Moreover, there was significant effect of temperature by host density interaction on numbers of progeny was performed $(P<0.05)$. The rate of oviposition by $E$. perniciosi was higher at $25^{\circ} \mathrm{C}$ than those at 15 and $20^{\circ} \mathrm{C}$ 
(Fig. 3a). At $25^{\circ} \mathrm{C}$, by increasing host density, the oviposition rates significantly increased $(P<0.001$; Fig. $3 b)$.

The instantaneous attack rate (a) and the estimated maximum number of scales parasitized (b) by E. perniciosi increased with increasing temperature from 15 to $25^{\circ} \mathrm{C}$. Correspondingly, the handling time $\left(T_{h}\right)$ for $E$. perniciosi tended to decrease as temperature increased (Table 2).
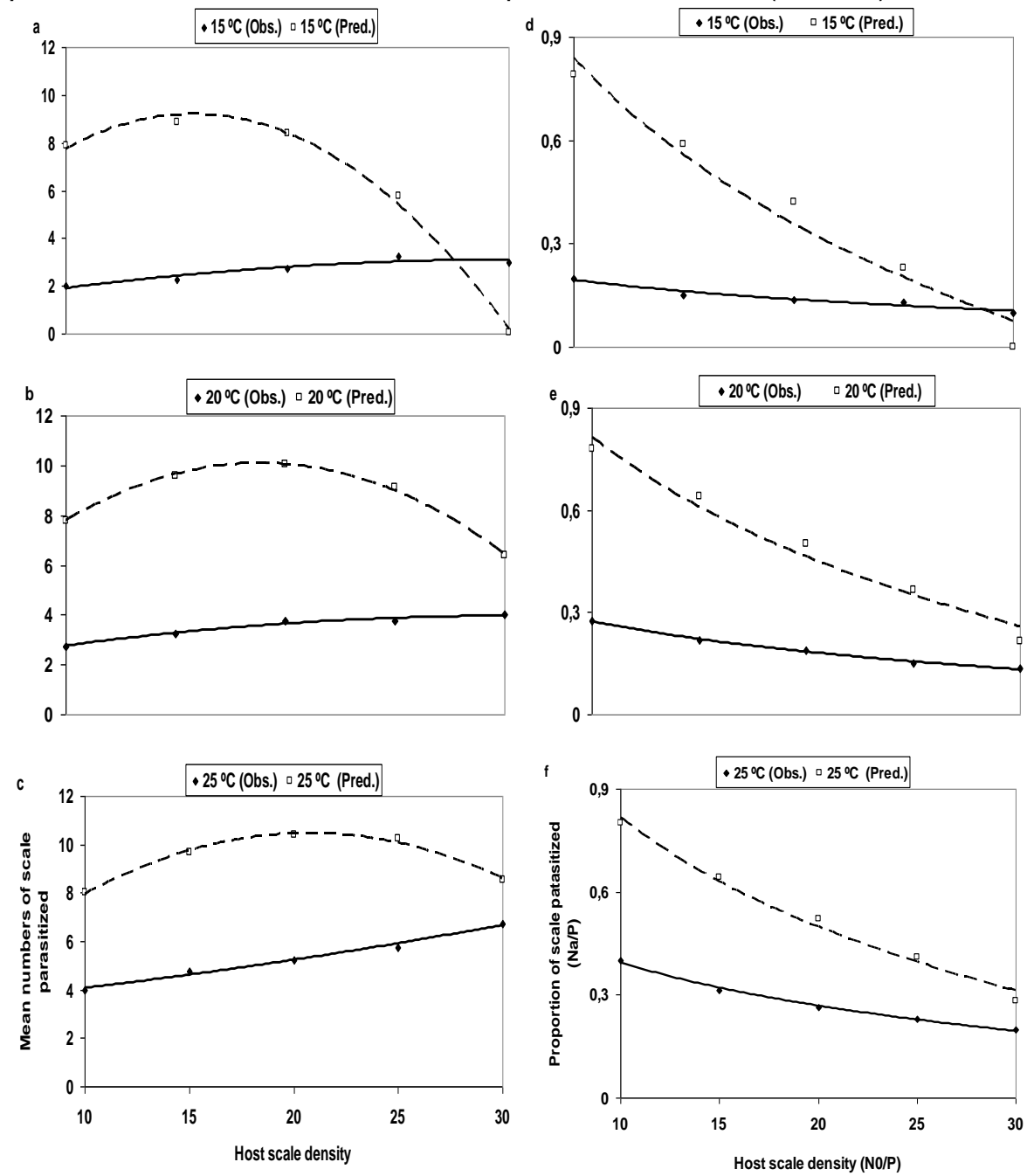

Fig. 2. Mean numbers (a-c) and proportion (d-f) of $Q$. perniciosus scales parasitized by $E$. perniciosi $\left(\mathrm{N}_{\mathrm{a}} / \mathrm{P}\right)$ in relation to different host densities $\left(\mathrm{N}_{0} / \mathrm{P}\right)$ and temperatures. The solid (observed) and dashed (predicated) lines represent the best-fitted type II functional response curves (a) and logistic regression models (b) for parasitoids attacking $Q$. perniciosus at different experimental temperatures. 

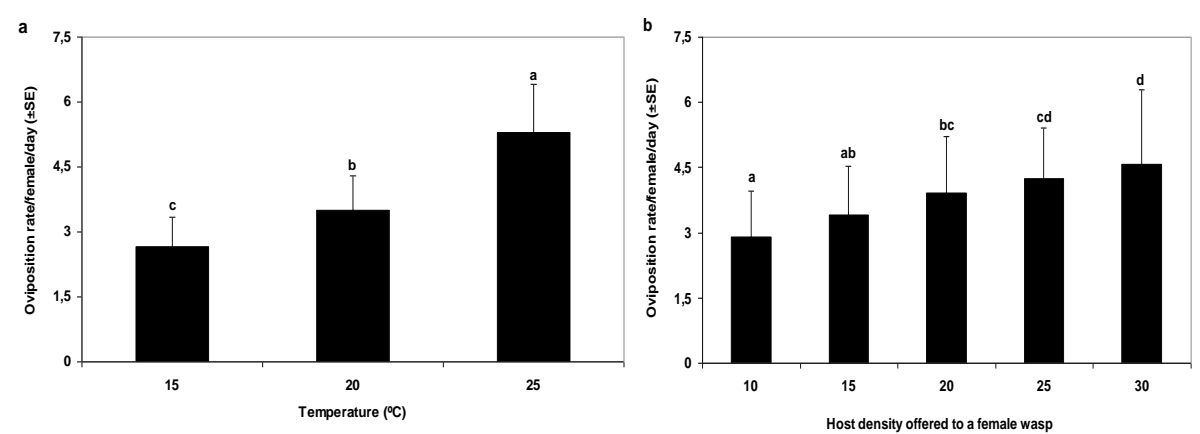

Fig. 3. Daily oviposition rate by $E$. perniciosi female at different temperatures (a) and host densities (b) at $25^{\circ} \mathrm{C}$. Values labeled with the diverse letters are significantly different $(P<0.05)$.

Table 1: Polynomial regression analysis between proportion of $Q$. perniciosus scales parasitized by $E$. perniciosi $\left(N_{a}\right)$ and the initial numbers of hosts $\left(\mathrm{N}_{0}\right)$ at different tested temperatures.

\begin{tabular}{|l|c|c|c|}
\hline Temperature $\left({ }^{\circ} \mathbf{C}\right)$ & Parameters & Estimates \pm SE & $\boldsymbol{P}$ \\
\hline \multirow{4}{*}{15} & Constant $\left(P_{0}\right)$ & $0.53 \pm 0.01$ & 0.02 \\
\cline { 2 - 4 } & Linear $\left(P_{1}\right)$ & $-0.054 \pm 0.002$ & 0.01 \\
\cline { 2 - 4 } & Quadratic $\left(P_{2}\right)$ & $0.003 \pm 0.0$ & 0.07 \\
\cline { 2 - 4 } & Cubic $\left(P_{3}\right)$ & $-4.0 E-005 \pm 0.0$ & 0.02 \\
\hline \multirow{4}{*}{20} & Constant $\left(P_{0}\right)$ & $0.43 \pm 0.11$ & 0.16 \\
\cline { 2 - 4 } & Linear $\left(P_{1}\right)$ & $-0.04 \pm 0.002$ & 0.003 \\
\cline { 2 - 4 } & Quadratic $\left(P_{2}\right)$ & $0.0 \pm 0.0$ & 0.005 \\
\cline { 2 - 4 } & Cubic $\left(P_{3}\right)$ & $-2.7 E-006 \pm 0.0$ & 0.09 \\
\cline { 2 - 4 } & Constant $\left(P_{0}\right)$ & $0.33 \pm 0.03$ & 0.11 \\
\cline { 2 - 4 } & Linear $\left(P_{1}\right)$ & $-0.034 \pm 0.006$ & 0.014 \\
\cline { 2 - 4 } & Quadratic $\left(P_{2}\right)$ & $0.001 \pm 0.0$ & 0.001 \\
\cline { 2 - 4 } & Cubic $\left(P_{3}\right)$ & $-4.7 E-005 \pm 0.0$ & 0.02 \\
\hline
\end{tabular}

The significant negative estimate for the parameter of $P_{1}$ indicates that the slope of the functional response curve is declining for $E$. perniciosi, thus a type II functional response at different temperatures (Mills and Lacan 2004).

Table 2: Estimates $( \pm \mathrm{SE})$ of instantaneous attack rate (a), handling time $\left(T_{h}\right)$, and maximum number of scale parasitized (b) for type II response of $E$. perniciosi parasitizing $Q$. perniciosus as host derived from Holling's model ( $T=1$ day).

\begin{tabular}{|l|c|c|c|c|c|c|}
\hline Temperature ( $\left.{ }^{\circ} \mathbf{C}\right)$ & $\mathbf{A}$ & $\mathbf{T}_{\mathbf{h}, \mathbf{h r} .}$ & $\mathbf{b}=\mathbf{T} / \mathbf{T}_{\mathbf{h}}$ & $\boldsymbol{F}$ & $\boldsymbol{P}$ & $\boldsymbol{R}^{\mathbf{2}}$ \\
\hline $\mathbf{1 5}$ & $0.32 \pm 0.06$ & $4.08 \pm 1.57$ & $5.46 \pm 1.88$ & 22.15 & 0.02 & 0.88 \\
\hline $\mathbf{2 0}$ & $0.56 \pm 0.32$ & $3.52 \pm 1.4$ & $6.24 \pm 2.6$ & 67.43 & 0.004 & 0.92 \\
\hline $\mathbf{2 5}$ & $1.13 \pm 0.39$ & $3.33 \pm 0.31$ & $7.29 \pm 0.64$ & 43.19 & 0.007 & 0.94 \\
\hline
\end{tabular}

\section{DISCUSSION}

\section{Functional response type of E. perniciosi and E. citrina}

A type II functional response is the most common type reported for most parasitoids (Matadha et al. 2005). In the current study, E. perniciosi exhibited a type II functional response, whereas $E$. citrina exhibited a type I response. The present results for E. perniciosi and E. citrina are similar to those reporting type I and II responses for the lab strain of Enarsia sp. nr. 
diaspidicola (Silvestri) and for the field strain of E. citrina (Matadha et al. 2005). Our results are the first to show a type II functional response for $E$. perniciosi which attacking $Q$. perniciosus. Although a parasitoid with a linear response does not exhibit the theoretical potential for control of the host required for classical biological control, the presence of a linear response is important for the continued interaction of the host and parasitoid (Hassell 1978). Parasitoids or predators that impose positively density dependence host mortality (i.e., type III) are supposed to manage the host population (Murdoch and Oaten 1975; Fernández-Arhex and Corley 2003). However, certain parasitoids and predators exhibiting type II response (i.e., inversely density dependent mortality) have been successfully established and managed host populations (Fernández-Arhex and Corley 2003). Hassell (1985) modeled the situation where parasitism rates are inversely density dependent in space. This pattern is thought to arise from a combination of little or no aggregation to high patch densities and handling time or egg limitation constraints. Provided the inverse density dependence is strong enough, this mechanism can stabilize host-parasitoid models.

In the current study, host density significantly influenced the proportion of scales parasitized by Encarsia spp. Previous studies reported that Aphytis species are highly dependent on climate and less on the host scale, whereas the reverse applies to Encarsia species (Rosen and Huffaker 1983). An attempt to determine the most efficient parasitoid of $E$. perniciosi and $E$. citrina was conducted using the functional response. We found that $E$. perniciosi is more effective than E. citrina in attacking greater proportions of scales as scale density increased. In average, the proportion of scales parasitized by E. perniciosi was more than double that of E. citrina. Jahn and Polesny (1999) in Austria reported that E. perniciosi is a more effective parasitoid of $Q$. perniciosus than Aphytis sp. under field conditions.

\section{Temperature-dependent functional response of $E$. perniciosi}

The information about the maximum daily rate of oviposition by $E$. perniciosi is lacking. Therefore, in the first experiment (i.e., effect of host density on functional response type), we used densities like those used by Matadha et al. (2005). However, based on the data obtained from the first experiment, we changed the host densities in the second experiment (i.e., effect of temperature on functional response of $E$. perniciosi) because we found that a female E. perniciosi parasitized more than $75 \%$ of hosts at 5 scales/fruit. Accordingly, we increased the tested densities of $Q$. perniciosus to $10,15,20$, and 30 scales/fruit. Moreover, we used 15,20 and $25^{\circ} \mathrm{C}$ like the average temperatures during seasons of activity for $E$. perniciosi under Austrian field conditions (i.e., autumn, spring, and summer, respectively).

Our results reveal that the type of response for E. perniciosi (i.e., type II) did not alter with changing temperature. No study has been conducted on the functional response of $E$. perniciosi to $Q$. perniciosus at a range of temperatures. Temperature and host density significantly affected the daily reproductive rate of $E$. perniciosi. The highest oviposition rate was obtained at $25^{\circ} \mathrm{C}$, and thus this condition seems to be more suitable for its activity and reproduction. The lowest rate was obtained at $15^{\circ} \mathrm{C}$. This implies that this condition not optimal for its searching and activity and appears to be near 
lower temperature thresholds for its oviposition. Danne et al. (2004) found that the lower and upper developmental threshold for E. perniciosi was 13 and $33^{\circ} \mathrm{C}$, respectively. The estimation of a temperature threshold for development and oviposition is essential for understanding the effectiveness of $E$. perniciosi in controlling Q. perniciosus populations under cooler temperature conditions. Our study in addition to Danne's study (Danne et al. 2004) confirms that E. perniciosi is unable to reproduce at temperatures below $15^{\circ} \mathrm{C}$. Although $E$. perniciosi can parasitize at $15^{\circ} \mathrm{C}$, such temperature may not be favorable for egg maturation and oviposition. Likewise, $15^{\circ} \mathrm{C}$ was not optimal condition for $E$. citrina reproduction on Hemiberlesia rapax (Comst.) (Logan and Thompson 2002). E. citrina females survived for longer durations at $15^{\circ} \mathrm{C}(34 \mathrm{~d})$, but they did not contribute significantly toward scale parasitism because of their proovigenic condition (Huffaker 1990).

The exactness of functional response in several previous studies is highly related to models and data analysis; the use of inappropriate models and methods of analysis may result in an incorrect estimation. Although the logistic model (Juliano 2001) easily illuminates the subtle differences in the type II and III responses, it fails to discriminate them from type I. Hence, efforts are needed to make a similar logistic model to differentiate type I from II and III. Ecologists normally face difficulties in determining functional response when the curve lies between type II and III. Hence, a suitable analysis that can best determine the functional response is highly needed, as it is of great practical relevance in estimating the bio-efficacy of natural enemy (Trexler et al. 1988). E. perniciosi has a type II response in the first experiment, and thus in the second experiment we directly used a logistic regression model using polynomial function to determine the correctness of the shapes (i.e., type) of E. perniciosi at different temperatures. For a type II response, there should be a decline in the proportion of parasitized hosts as the density increases, so that the linear term should be negative. The significant negative values for the linear parameter obtained in this study at different temperatures confirm the type II response for E. perniciosi.

Although Holling's disc equation (1959) is widely used to estimate parameters of type II functional response, some authors emphasize on the limitation of Holling's disc equation, and suggest Roger's random parasitoid/predator equation (1972) as an alternative, which is more appropriate when prey depletion (for a predator) or re-encounter (for a parasitoid) may be occurs during the experiment (Juliano 2001). Holling's disc equation can be used only when Roger's model does not enable the researcher to estimate valid parameters. For example, Mohaghegh et al. (2001) used Holling's model because Rogers's model provides invalid parameters for their data set. Similarly, Holling's model adequately described the decrease in parasitism rate with increasing host density at all experimental temperatures, and thus provided valid parameters for our data set. Holling's model is really designed for predators, however it is appreciate for proovigenic parasitoids (Chong, $\mathrm{JH}$., personal communication).

The instantaneous attack rate and handling time were defining parameters of type II responses for E. perniciosi at different temperatures. The values of instantaneous attack rate and handling time differed when 
exposed to different temperatures, which indicated that they have different abilities to respond to increase host densities at different temperatures. This indicates that parasitoids exhibiting similar functional response curves (i.e., type) under different conditions cannot be deemed to respond similarly. $E$. perniciosi has the highest instantaneous attack rate and the shortest handling time at $25^{\circ} \mathrm{C}$. This reveals that the parasitoid will spend a larger amount of time with non-searching activities (e.g., resting) at lower temperatures, while more searching and activity would be expected at higher temperatures. As consequence, $E$. perniciosi parasitized more hosts at $25^{\circ} \mathrm{C}$, and thus $E$. perniciosi seemed to be an effective candidate to control Q. perniciosus from late spring to early summer in Austria and Egypt, where the temperature is frequently around $25^{\circ} \mathrm{C}$. Handling time is a general term that includes time for killing a prey or antennating and parasitizing a host, time for resting, preening and time for water ingestion (or sap feeding in parasitoids). We cannot determine how E. perniciosi allocates time to different non-foraging activities.

The handling time derived from the first experiment for E. perniciosi was similar to that measured from second experiment at $25^{\circ} \mathrm{C}$. However, the instantaneous attack rate was differed. The difference may be the influence of $\mathrm{rh} \%$ or the differences in host densities between both experiments. It appeared that the parasitoids' handling times derived from the functional response models for $E$. perniciosi tended to be overestimated because the parasitoids did not spend all the available time in foraging but often engage in other activities (e.g., searching, feeding, grooming, and resting). Thus, it is essential to obtain actual handling time through behavioral observation. Direct observations showed a female usually took about $32-37 s \quad(n=10)$ to oviposit in a host; this value was much lower than that obtained from the experimental data at each temperature. This was the case, because the estimated time not included the time of non-searching activities.

The efficiency of a parasitoid from laboratory-derived functional response data reflects the potential of $E$. perniciosi as a bio-control candidate. Pak and van Lenteren (1988) mentioned that strains that showed a high potential in the laboratory also have the ability to perform well in the field. However, we caution that because the observed pattern may be an experimental artifact, i.e. unnatural (Kareiva 1990) due to the differences in the size of the area parasitoids have to search to find hosts (O'Neil 1989), and thus not reflecting the true effect of parasitoid on its host population in the field (van Lenteren and Bakker 1978). Such studies are, however, useful in providing the first step for comparing the efficiency of different species/strains (Overholt and Smith, 1990) and also provide a valid means of comparing host finding abilities of candidate natural enemies (Munyaneza and Obrycki, 1997).

Due to the inversely density-dependent parasitism for E. perniciosi in response at $25^{\circ} \mathrm{C}$, it seems to be more effective in low host densities and relatively moderate temperature and this result has to be considered in future bio-control and mass rearing programs. Hence, releasing the parasitoid in the beginning of growing season on low host populations or using the chemical pesticides to reduce the host population before its release might provide more control. The data obtained here at constant temperatures will provide a 
direction for future research on evaluating the impact of $E$. perniciosi in infested fruit orchards under variable environment conditions. Further studies are highly needed to determine the effect of host stage and parasitoid's age on response of $E$. perniciosi under laboratory conditions. Moreover, under field conditions, factors such as large searching arenas (Wiedenmann and O'Neil 1991), effect of common predators like as ants and spiders, and spatial complexity (Kareiva 1990) may adversely influence the effectiveness of natural enemies. By understanding these interactions, we will be able to develop suitable strategies for the future bio-control of $Q$. perniciosus.

\section{ACKNOWLEDGMENTS}

The authors thank the Egyptian Cultural Office in Vienna for supporting this work through a join cooperation scholarship between Mansoura University in Egypt and Universität für Bodenkultur (BOKU) in Austria. Thanks are extended to Prof. Dr. C. Staufer, Dr. G. Hoch (IFFF, BOKU), and Prof. Dr. J.H. Chong (Clemson University) for reviewing the manuscript and offering helpful comments. Thanks also to Dr. P. Baier (IFFF) for helping in statistics.

\section{REFERENCES}

Abd El-Kareim Al, Abdel-Salam AH, Abdel-Baky NF, Bayoumy MH, 2005. The role of parasitoids in controlling San Jose scale, Qudaraspiditiotus perniciosus (Hem., Diaspididae) populations as a new introduced pest to Egypt. J. Agri. Sci., Mansoura Univ. 30(12), 8193-8200.

Baroffio C, 1997. Some aspects of the biology of Encarsia perniciosi (Tower) in its host, Quadraspidiotus perniciosus (Comstock), and application of the results in a biological control program in central Switzerland (Canton Zug). Mitteilungen der Schweizerischen Entomologischen Gesellschaft 70, 323-333.

Bayoumy MHM, Abdel-Kareim Al, Abdel-Salam AH, Abdel-Baky NF, Schopf A, 2009. Host age preference and host searching efficiency of Encarsia citrina Craw. (Hym., Aphelinidae), a parasitoid of Euonymus scale, Unaspis euonymi (Comstock) (Hem., Diaspididae) in Austria. Deutsche Gesellschaft für allgemeine und angewandte Entomologie, March 1619, 2009, Göttingen, Germany.

CoStat Software, 2005. Microcomputer program analysis, version 6.3. CoHort Software, Berkely, CA, USA.

Daane KM, Glenn YY, Karen S, Walter JB, 2004. San Jose scale and its natural enemies. Investigating Natural and Augmented Controls. CTFA Annl. Res. Report: 87-97.

Fathipour Y, Hosseini A, Talebi A, Moharramipour S, 2006. Functional response and mutual interference of Diaeretiella rapae (Hym., Aphidiidae) on Brevicoryne brassicae (Hom., Aphididae). Entomol. Fenn. 17, 90-97.

Fernández-Arhex V, Corley JC, 2003. The functional response of parasitoids and its implications for biological control. Biocontrol Sci. and Tech. 13, 403-413.

Getz WM, Mills NJ, 1996. Host-parasitoid coexistence and egg-limited encounter rates. American Naturalist, 148, 333-347. 
Hassell MP, 1978. The Dynamics of Arthropod Predator Prey Systems Monographs in Population Biology 13. Princeton, NJ: Princeton University Press, $237 \mathrm{pp}$.

Hassell MP, 1985. Parasitism in patchy environments: inverse density dependence can be stabilizing. IMA Journal of Mathematics Applied in Medicine and Biology, 1, 123-133.

Hassell MP, 2000. The spatial and temporal dynamics of host parasitoid interactions. Oxford Series in Ecology and Evolution. Oxford University Press, London, UK, $198 \mathrm{pp}$.

Holling CS, 1959. Some characteristics of simple types of predation and parasitism. Can. Entomol. 91, 385-398.

Holling CS,1961.Principles of insect predation.Ann.Rev. Entomol. 6, 163-182.

Holling CS, 1965. Functional response of predators to prey density and its role in mimicry and population regulation. Memoirs of Entomological Society of Canada 45, 3-60.

Huffaker CB, 1990. Effect of environmental factors on natural enemies of armored scale insects. In: Armored scale insects their biology, natural enemies and control. Ed by Rosen D, vol. B (World crop pests; 4A, 205-217. Elsevier Barking, United Kingdom.

Jahn S, Polesny F, 1999. Population dynamics of San Jose scale and San Jose scale parasitoids in three different sites in Austria. Bulletin OILB/SROP. International Organization for Biological and Integrated Control of Noxious Animals and Plants (OIBC/OILB), West Palaearctic Regional Section, Dijon, France. 22 (7): 201-202.

Jolly CL, 1962. Biological control of San Jose scale in Himachal Pradeshretrospect and prospect. Himachal Hort. 2\&3, 163-168.

Juliano SA, 2001. Non-linear curve fitting: Predation and functional response curves. Design and analysis of ecological experiments. Ed. by Scheiner SM, Gurevitch J, 2nd edition, 178-196. New York: Chapman and Hall.

Kaiser C, Sheard AG, 2006. Integrated Pest \& Disease Management (IPDM) of Cherries in Kwazulu - Natal. KZN Department of Agriculture and Environmental Affairs. KZN Agri Report NA 2001-2006, 33 pp.

Kareiva $P, 1990$. The spatial dimension in pest-enemy interaction. In: Mackauer M, Ehler LE, Roland J (eds) Critical Issues in Biological Control, Intercept, Anover, Hants, pp. 213-227.

Kozàr F, Jasnoshi VA, Kostantinova GMK, 1982. Comparative evaluation of the distribution of scale-insects (Hom., Coccoidea) and their parasites in Georgia (USSR) and in Turkey. Zeitschrift fur Angewandte Entomologia 93 (4): 333-338.

Logan DP, Thompson C, 2002. Temperature-dependent development of parasitoids on two species of armored scale insects. New Zealand Plant Protection Volume 55, 2002. Proceedings of a conference, Central Hotel, Rotorua, New Zealand, 13-15 August 2002. New Zealand Plant Protection Society, Rotorua, New Zealand, 361-367.

Malipatil MB, Dunn KL, Smith D, 2000. An Illustrated Guide to the Parasitic Wasps Associated with Citrus Scale Insects and Mealy bugs in Australia. Department of Natural Resources and Environment, KnoxWeld, Victoria, Australia. pp. 152. 
Matadha D, Hamilton GC, Lashomb JH, Zhang J, 2005. Ovipositional preferences and functional response of parasitoids of euonymus scale, Unaspis euonymi (Comstock) and San Jose scale, Quadraspidiotus perniciosus (Comstock) (Hom., Diaspididae). Biol. Control 32, 337-347.

Mills NJ, Lacan I, 2004. Ratio dependence in the functional response of insect parasitoids: evidence from Trichogramma minutum foraging for eggs in small host patches. Ecol. Entomol. 29, 208-216.

Mohaghegh J, DeClercq P, Tirry L, 2001. Functional response of the predators Podisus maculiventris (Say) and Podisus nigripinus (Dallas) (Het., Pentatomidae) to the beet armyworm, Spodoptera exigua (Hubner) (Lep., Noctuidae): effect of temperature. J. Appl. Entomol. 125, 131-134.

Moursi K.S, Mesbah HA, Mourad AK, Abdel-Razak SI, 2008. Ecological studies on San Jose scale, Diaspidiotus perniciosus (Comstock) (Hom., Diaspididae) as a new insect pest on pear trees in Burg El-Arab area, Alexandria, Egypt. Commun. Agric. Appl. Biol. Sci. 73(3):439-50.

Munyaneza J, Obrycki JJ, 1997. Functional response of Coleomegilla maculata (Col. Coccinelidae) to Colorado potato beetle eggs (Coleoptera: Chrysomelidae). Biol. Control 8, 215-224.

Murdoch WW, Oaten A, 1975. Predation and population stability. Advances in Ecological Research 9, 1-131.

Neuffer G, 1990. The abundance and increase of the San Jose scale Quadraspidiotus perniciosus Comst. and its natural enemy Prospaltella perniciosi Tow. A summary of 30 years' investigations. J. Gesunde Pflanzen, 42(3): 89-96.

Nicholson AJ, Bailey VA, 1935. The balance of animal populations. Part I. Proc. Zool. Soc. London 3, 551-598.

O'Neil RJ, 1989. Comparison of laboratory and field measurements of the functional response of Podisus maculiventris (Het., Pentatomidae). J. Kansas Entomol. Soc. 62, 148-155.

Overholt WA, Smith JW, 1990. Comparative evaluation of three exotic insect parasites (Hym., Braconidae) against the southwestern corn borer (Lep., Pyralidae) in corn. Environ. Entomol. 19, 345-356.

Pak GA, van Lenteren JC, 1988. Criteria and methods for the pre-release evaluation of different Trichogramma spp. strains. In: Trichogramma and other egg parasitoids. Ed. by Voegele J, Wagge J, van Lanteren $\mathrm{JC}$, proc. of $2^{\text {nd }}$ Int. Sym. on Trichogramma, Guangzhou, PR China, No. 43 Les colloques de 1 'INRA, Paris, 433-442.

Pakyari H, Fathipour Y, Rezapanah M, Kamali K, 2009. Temperaturedependent functional response of Scolothrips longicornis (Thy., Thripidae) preying on Tetranychus urticae. Journal of Asia-Pacific Entomology (in press).

Rogers D, 1972. Random search and insect population models. J. Anim. Ecol. 41, 369-383.

Rosen D, Huffaker CB, 1983. An overview of desired attributes of effective biological control agents, with particular emphasis on mites. Pages 211. In: Biological Control of Pests by Mites. Ed by Hoy MA, Cunningham GL, Knutosn L, University of California, Division of Agriculture and Natural Resources, Publication 3304. 
Sahai B, Joshi LD, 1965. Bionomics and biological control of San Jose scale (Quadraspidiotus perniciosus Coms.) in U.P. Punjab Hort. J. 5, 37-45.

Solomon ME, 1949. The natural control of animal population. J. Anim. Ecol. $18,1-35$

SPSS Inc., 2006. SPSS for Windows Release 15.0. SPSS Inc., Chicago, IL.

Trexler JC, Charles EM, Travis J, 1988. How can the functional response best be determined? Oecologia 76, 206-214

Van Driesche RG, Bellows TS, 1996. Biological Control. Chapman \& Hall, New York, USA.

Van Lenteren JC, 1986. Evaluation, mass production, quality control and release of entomophagous insects. In: Biological Plant and Health Protection. Ed. by Franz JM, Progress in Zoology Series 32, Fischer, Stuttgart, pp. 31-56.

Van Lenteren JC, Bakker K, 1978. Behavioral aspects of the functional response of a parasite (Pseudeucoila bochei Weld) to its host (Drosophila melanogaster). Neth. J. Entomol. 28, 213-233.

Wiedenmann RN, O'Neil RJ, 1991. Searching behavior and time budgets of the predator Podisus maculiventris. Entomol. Exp. Appl. 60, 83-93.

\footnotetext{
الإستجابات الوظيفية لطفيلEncarsia citrine و Encarsia erniciosi

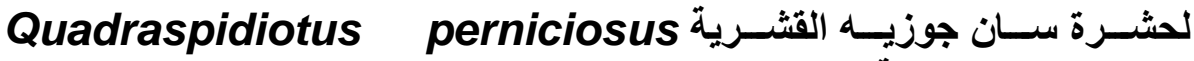

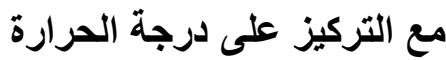

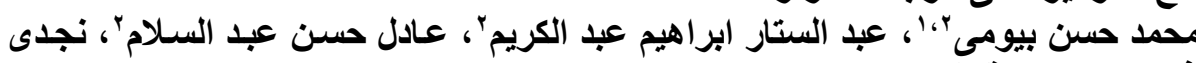

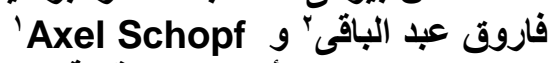

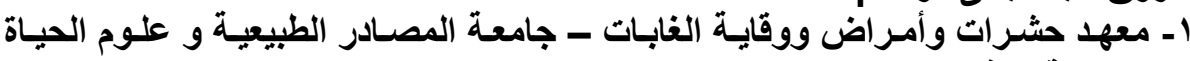

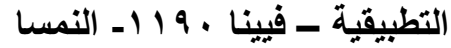
r ـ قسم الحشرات الإقتصادية ـ كلية الزراعة ـ جامعة المنصورة ـ مصر

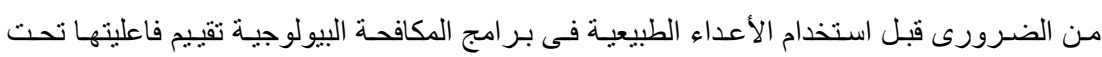

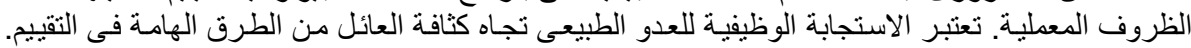

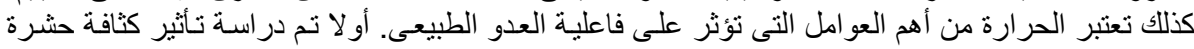

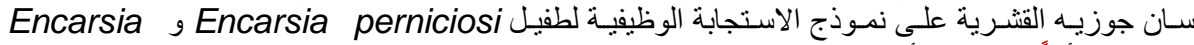
citrina

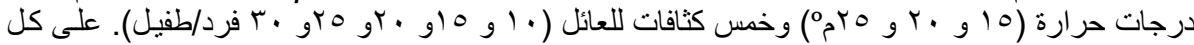

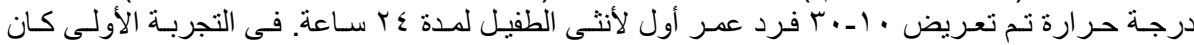

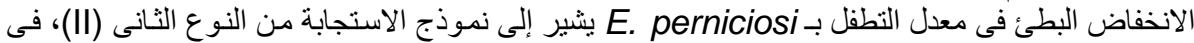

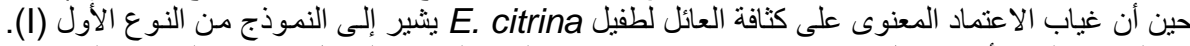

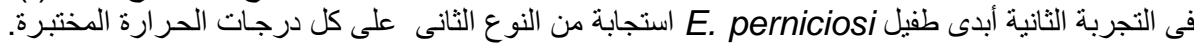

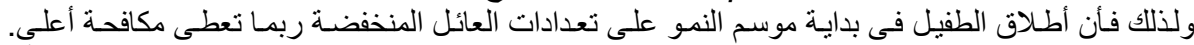

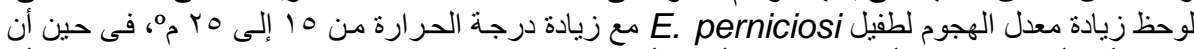

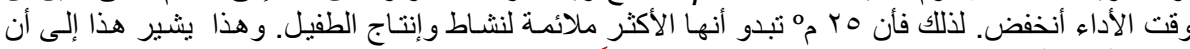

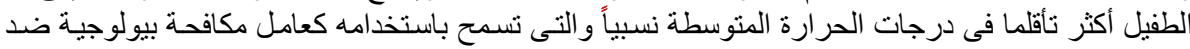
الحشرة خلال موسم النمو حتى فى البلاد ذات خطوط العربط العرض العالية.
} 